\title{
Patients' and general practitioners' satisfaction with information given on discharge from hospital: audit of a new information card
}

\author{
David A Sandler, Claire Heaton, Stephen T Garner, J R A Mitchell
}

Department of Medicine and Pharmacy, University Hospital, Queen's Medical Centre, Nottingham NG7 2UH

David A Sandler, MD,

lecturer

Claire Heaton, student

pharmacist

Stephen T Garner, BSC, chief pharmacist

J R A Mitchell, MD, professor of medicine

Correspondence to: $\mathrm{Dr}$ Sandler.

Br.Med f 1989;299:1511-3

\begin{tabular}{|c|c|c|c|c|c|c|c|c|c|c|c|c|}
\hline \multirow{2}{*}{\multicolumn{3}{|c|}{$\begin{array}{l}\text { UNIVERSTYY HOSPITAL, NOTTINGHAM } \\
\text { Information on Discharged Patients } \\
\text { G.P.COPY }\end{array}$}} & \multirow{4}{*}{\multicolumn{6}{|c|}{$\begin{array}{l}\text { GENERAL PRACTIIIONER INFORMATION } \\
\text { Will NOT appear on patients cOpY } \\
\text { DIAGNOSIS: } \\
\text { INPATIENT PROBLEMS: }\end{array}$}} & \multicolumn{4}{|c|}{ INFORMATION GIVEN TO PATIENI } \\
\hline & & & & & & & & & \multicolumn{2}{|c|}{$\begin{array}{l}\text { You have been in hospital } \\
\text { because of: }\end{array}$} & \multicolumn{2}{|c|}{ 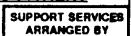 } \\
\hline \multirow{3}{*}{\multicolumn{3}{|c|}{$\begin{array}{l}\text { Letter to Dr. } \\
\text { Patien Name } \\
\text { Adoress }\end{array}$}} & & & & & & & \multirow{3}{*}{\multicolumn{2}{|c|}{ | SPECIAL INSTRUCTIONS: }} & \multirow{7}{*}{\multicolumn{2}{|c|}{ 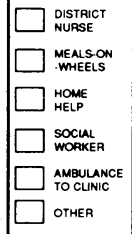 }} \\
\hline & & & & & & & & & & & & \\
\hline & & & & & & & & & & & & \\
\hline \multirow{5}{*}{\multicolumn{3}{|c|}{ 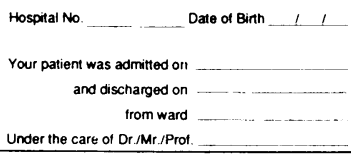 }} & \multirow{5}{*}{\multicolumn{6}{|c|}{ YOF THIS LETTER }} & \multirow{5}{*}{\multicolumn{2}{|c|}{ 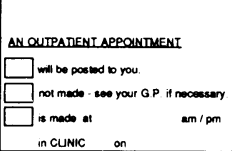 }} & & \\
\hline & & & & & & & & & & & & \\
\hline & & & & & & & & & & & & \\
\hline & & & & & & & & & & & & \\
\hline & & & & & & & & & & & & \\
\hline DETAILS OF D & HARG & MEDICATION & & ge & & & Date 1 & 11 & Signatu & & & O/SHO \\
\hline Name of & Dose & Special & & EN TO TN & WE OR USE MEOCAT & & Days & \begin{tabular}{|l} 
When sppoy \\
\end{tabular} & uns at: & & & \\
\hline Medication & & Instructions & 8 an & $10 \mathrm{am}$ & & & supplioes & $\begin{array}{l}\text { Sotin mase } \\
\text { trom GP } \\
\end{array}$ & Stop & REASON FOR MEDI & ICATION & Disp. \\
\hline & & & & & & & & & & & & \\
\hline & & & & & & & & & & & & \\
\hline & & & & & & & & & & & & \\
\hline & & & & & & & & & & & & \\
\hline & & & & & & & & & & & & \\
\hline & & & & & & & & & & & & \\
\hline & & & & & & & & & & & & \\
\hline
\end{tabular}

Top (green) sheet of information card given to patients at discharge from hospital. This top copy doubles as the "interim discharge letter" for the general practitioner complete a questionnaire giving their views on the legibility, helpfulness, quality, and quantity of the information they received. Copies of all the information cards were scrutinised for completeness.

Main results-The results were based on 208 (76\%) forms returned by patients and $214(78 \%)$ forms returned by general practitioners. Information was considered very helpful or quite helpful according to $170(83 \%)$ forms from patients and $197(92 \%)$ forms from general practitioners; sufficient information was provided according to 160 and 182 forms. Most patients and nearly all general practitioners thought it was a good idea to provide this information for patients at discharge. According to 125 forms from patients and 188 from general practitioners the information card was very easy or quite easy to read;
155 patients had read it at least twice and 149 were likely to refer to it again.

Other results - The written information about the patient, the diagnosis, and what the patient had been told was generally well completed, although the date of discharge was omitted from $42(15 \%)$ cards. Details of drugs prescribed at discharge were generally thorough.

Conclusions-Giving an information card to all patients at discharge was feasible and favoured by most patients and their general practitioners. Having made minor changes in design, we think that we have produced an information card that is a convenient size and will improve communication between patients, their general practitioners, and hospital doctors. We now issue this card routinely to all patients discharged from our ward and hope that it might be widely adopted. copy of the card in the form of an interim discharge letter to be delivered to their general practitioner. Patients and general practitioners were asked to

\section{Introduction}

Patients who were given written information when discharged from hospital were better informed about their illness and treatment than those who were not given such information in a previous study.' From the constructive comments received during that pilot study we redesigned our four sided patient information booklet as an A4 sized card. We now report our experience with the new design in 275 consecutive patients discharged from hospital and an assessment by both the patients and their general practitioners of this new design.

\section{Methods}

PATIENT'S INFORMATION CARD

The card base is overlaid by two similar sheets of non-carbon return paper. Information written on the green top sheet (which later becomes the interim discharge letter) (figure) is copied on to the yellow middle sheet and on to the white card base which, after the top two copies have been removed, is folded into three and put in a clear plastic wallet and given to the patient. The card is divided into four sections: "personal details," "general practitioner information" and the details written here are not copied through to the patient's card, "information given to patient," and "details of discharge medication." The first three sections are on the top half of the card and the details of prescriptions are given on the bottom of the card.

\section{DISCHARGE OF PATIENTS}

All patients who were discharged home from the care of any of three consultants on one general medical ward at this hospital over 16 weeks were given an information card. Patients were given the green top copy, serving as the interim discharge summary, and a letter, asking their general practitioner to assess the new design by completing an enclosed reply paid card, to deliver to their family doctor. The yellow "case notes" copy was retained. 
General practitioners' and patients' assessments of the legibility and helpfulness of the information card. Figures are numbers (and percentages)

\begin{tabular}{lccc}
\hline Answers to questions & $\begin{array}{c}\text { Replies from } \\
\text { general practitioners } \\
(\mathrm{n}=214)\end{array}$ & $\begin{array}{c}\text { Assessment of } \\
\text { casenote copy } \\
(\mathbf{n}=275)\end{array}$ & $\begin{array}{c}\text { Replies from patients } \\
(\mathrm{n}=208)\end{array}$ \\
\hline Very easy & $\begin{array}{c}\text { How easy was the information card to read? } \\
116(54)\end{array}$ & $133(48)$ & $52(25)$ \\
Quite easy & $72(34)$ & $99(36)$ & $73(35)$ \\
A little difficult & $21(10)$ & $35(13)$ & $53(25)$ \\
Very difficult & $2(1)$ & $8(3)$ & $25(12)$ \\
Unanswered & 3 & 0 & 5 \\
Very helpful & How helpful was the information card? & $74(36)$ \\
Quite helpful & $103(48)$ & & $96(46)$ \\
Not too helpful & $94(44)$ & $23(11)$ \\
Unhelpful & $12(6)$ & $10(5)$ \\
Unanswered & $1(0 \cdot 5)$ & 5 \\
\hline
\end{tabular}

\section{ASSESSMENT}

Each study patient was asked to fill in a questionnaire assessing the information card either in the medical outpatient clinic or by post about three weeks after discharge using a reply paid envelope for return to the hospital. Any patient who was readmitted early to the hospital was given the questionnaire at that time. If such patients again became eligible for entry into the study at a subsequent discharge they were given a new information card. Each general practitioner who received a copy of the new information card as an interim discharge letter was asked for an assessment on an accompanying reply paid card.

\section{QUESTIONNAIRES}

Patients and general practitioners were asked for the best answer from three or four choices (see table). Patients were asked how often they had read the card since discharge, whether anyone else had read it, and whether they would refer to it again in the future. Patients and general practitioners were asked how easy it was to read the handwriting on the card, how helpful they found the card, whether they thought the information in the card was adequate, and what they thought of giving a card like this to all patients discharged from hospital. A space was available for comments.

\section{ANAL YSIS OF COPIES OF INFORMATION CARDS}

All of the middle copies of the information card were reviewed by one of two investigators (DAS, $\mathrm{CH}$ ). Note was made of which parts were complete or incomplete and of the legibility of the copy.

\section{Results}

During the 16 weeks 275 discharges of 258 patients were included in the study. Sixteen patients were discharged from the ward (and therefore entered into the study) twice and one patient was discharged (and included) three times during the study. The study group of 150 men $(58 \%)$ and 108 women had a mean age of 60 years (range 16-100 years) and a mean duration of admission of five days (median four days; range 1-29 days).

\section{COMPLETENESS OF INFORMATION CARDS}

Copies of all 275 information cards were reviewed. All had the patient's name and address, the name of the ward they had been staying on, the consultant's name, the general practitioner's name, the hospital number, and the date of admission to the ward, but the date of discharge was omitted from $42(15 \%)$ cards. Of the section copied only to the general practitioner, the "diagnosis" was omitted on 11 cards, "inpatient problems" were entered on 122, and comments were made on 114. In the section for "information given to patient" 17 cards did not state why the patient had been in hospital, and only 74 listed any "special instruc- tions." Use of "support services" was entered on 21 cards. Outpatient follow up was intended for 199 patients (72\%): 179 of these cards gave details of the appointment, and 20 patients were to receive details by post. Outpatient appointments were deemed unnecessary for 58 patients, and on 18 cards there was no indication of the need for follow up.

For the 251 patients given a prescription at discharge the doses of all prescribed drugs were given on 242 cards $(96 \%)$, instructions on how and when to take all treatment on $239(95 \%)$, the number of days that each of the drugs would be supplied on $228(91 \%)$, instructions of what to do when each drug ran out on 221 $(88 \%)$, and the reason the drug was prescribed on 240 cards $(95 \%)$. On all but 15 cards it was possible to determine which doctor had completed the card, and the table gives the assessment of the legibility of the copies.

\section{GENERAL PRACTITIONERS' ASSESSMENT}

A total of $214(78 \%)$ replies were received from general practitioners. We do not know whether patients delivered the other 61 reply cards to their general practitioners or whether the general practitioners received them and did not return them. The table gives the general practitioners' assessment of the legibility and helpfulness of the information on the card. The information on $182(85 \%)$ cards was considered to be sufficient, and on 204 (95\%) cards general practitioners said they thought that giving a copy of this information to the patient was a good idea, while on eight (4\%) they were not sure. On 51 (23\%) cards general practitioners made comments and criticisms; 15 said that the $\mathrm{A} 4$ size of the letter was too big for the standard record envelopes.

\section{PATIENTS' ASSESSMENT}

A total of $208(76 \%)$ questionnaires were completed by patients: $120(58 \%)$ were returned from the outpatient clinic, $67(32 \%)$ were returned by post, and 21 $(10 \%)$ were completed by patients when they were readmitted. The card had been shown to 113 spouses $(54 \%), 57$ other family members $(27 \%), 71$ general practitioners $(34 \%)$, and only 33 patients $(16 \%)$ had shown the card to no one else. Thirty eight patients $(18 \%)$ had read the card once, $51(25 \%)$ had read it twice, and $104(50 \%)$ had read it more than twice; 97 patients $(47 \%)$ said they would definitely read the card again, $52(25 \%)$ said they would probably read it again, $36(17 \%)$ said possibly, and $14(7 \%)$ said they would not read it again. The table gives the patients' assessment of the legibility and helpfulness of the cards. There was sufficient information on the card for 160 patients $(77 \%)$, too much for three, and 35 wished for more. The information card was considered a good idea by 186 of the 208 patients $(89 \%)$; 56 patients $(27 \%)$ added comments to the questionnaire, 20 mentioning legibility.

\section{Discussion}

We carried out this study to determine if a newly designed information card for patients being discharged from hospital was acceptable to the patients and their general practitioners, and if it was feasible to make this a standard procedure on one general medical ward. We found that the card satisfied all these aims. Giving patients a card combining discharge information and the prescription was suggested as a way of informing general practitioners quickly'; our information card was based on this principle.

The identification of the patient and the dates of admission and discharge are important on these letters." Although most of the "personal information" was complete, on $15 \%$ of the cards the date of discharge was 
omitted. The reason was likely to be that the date of discharge was in the "personal details" section of the card, completed by clerical staff on admission to the ward, and could easily be overlooked by medical staff who completed the rest of the card just before discharge. The space for the discharge date will therefore be made more prominent.

General practitioners need to know what diagnosis was made, and 264 of 275 information cards stated this. Because some sections of the card were not completed, and it was not clear why, we shall add boxes labelled "not applicable," which can be ticked. General practitioners also find it helpful to know what the patient knows, ${ }^{3}$ and 258 cards stated what the patient was told when discharged. The details of outpatient follow up were given on 179 of 199 cards. This not only was useful to patients and their general practitioners but also eliminated the need for an extra appointment card. Full details were given in most cases of prescriptions issued to patients, undoubtedly because a prescription was a prerequisite for the discharge of 251 of the patients in the study. Much prescription information on the cards could be completed by ticking boxes, and this undoubtedly facilitated completion.

The legibility of the handwriting on the cards was a concern, as well as the clarity on the top and middle copies. On 232 forms the retained middle copies were considered to be at least "quite easy" to read, and 188 of the forms that went to general practitioners were at least "quite easy," with over half of the forms "very easy" to read. Although 25 patients found their card "very difficult" to read, 125 were able to read it "quite easily." This was gratifying because the patient receives the bottom copy, which allowed us to provide general practitioners with information that is not given to the patient.

On nearly all the questionnaires general practitioners said that giving' a copy of this information to their patients was a good idea; a few were undecided but none thought it ill advised. Most patients (186; 89\%) also thought it a good idea. A high proportion of general practitioners and patients considered the information helpful and satisfactory. On a few forms general practitioners commented that the size of the letter was too big to go into the standard NHS envelopes, which suggests that these envelopes have outlived their useful life. A4 is the standard used for clinic letters and full discharge summaries, and we think that trying to condense the information on smaller paper would make it more difficult for the patients to read. We were pleased that two thirds of the patients had read the cards at least twice, that many had shown them to other people, and that about three quarters of patients would probably read them again.

As most of the general practitioners and patients thought the card was a good idea and responded favourably to the questionnaires, we now issue the card, with the slight modifications we described, to all patients who are discharged from our ward. The Department of Health has recently issued a health circular on the discharge of patients from hospital, ${ }^{+}$ which emphasises that patients and their relatives should be fully informed before discharge and important points confirmed in writing, particularly details of drug treatment. We believe that the design of our information card helps to comply with these recommendations and hope that it will be adopted in other hospitals in an effort to improve communication between the patients and medical staff.

We thank ward receptionist Christine Morrell and the nursing and medical staff of ward D56, particularly $\mathrm{Dr}$ Rachael Garner and Dr James Kent, for their patience and cooperation during this study. We also thank the nursing staff of clinic $\mathbf{2}$ for their help in distributing and collecting patient questionnaires; the patients and the general practitioners of Nottingham who replied to our survey; and Professor J R Hampton and Dr R G Wilcox for permission to study their patients. Special thanks are due to Mr P Ball and Mr L Cochrane for help in designing and producing the information cards.

1 Sandler DA, Mitchell JRA, Fellows A, Garner ST. Is an information booklet for patients leaving hospital helpful and useful? Br Med $\mathcal{F}$ 1989;298:870-4

2 Kendrick AR, Hindmarsh DJ. Which type of hospital discharge report reaches general practitioners most quickly? BrMed f 1989;298:362-3.

3 Tulloch AJ, Fowler GH, McMullan JJ, Spence JM. Hospital discharge reports: content and design. Br Med f 1975;iv:443-6.

4 Department of Health. Discharge of patients from hospital. (Health circular.) London: Department of Health, 1989 (HC (89) 5.)

(Accepted 25 September 1989)

\section{MATERIA PARAMEDICA}

\section{Multiple plaques}

This is not, as you might think, about pathology; it is about applied physiology. Shortly before the second world war I attended St Stephen's Hospital in Fulham Road, west London, regarding a job application. I arrived in a state of acute physical discomfort. Mercifully, in a side passage leading off the main corridor there was a door bearing an elegant enamelled plaque, and the word "Lavatory." I flung the door open, only to be confronted by a washbasin. Frustration was hardly mitigated by the realisation that here "lavatory" was used in its correct etymological sense, namely, a place for washing oneself (L lavo, to wash; lavatio, a bath). In the facing wall of the passage there was a door bearing a plaque and the letters "WC." I was greatly relieved.

The word "lavatory" is merely one in a long line of euphemisms extending over the centuries. Most euphemisms depreciate with constant use and are then replaced by new ones (St Stephen's was built in 1878). I am quite happy with the currently adopted "loo" and think it will stick since excretion is no longer a taboo subject.

The problem of finding a loo in an emergency is not always topographical; it may be linguistic. When travelling abroad, surely the local word should be included in every traveller's top 20 words. The Collins phrase books are helpful, but seem to be the product of multiple authorship and sometimes give different equivalents for "toilet" and for "lavatory." Spoken inquiry will usually yield the right answer in any west European country if one's utterance sounds like "toe-ull-et." In France and Germany "WC" is also used, doubtless from vestigial respect for
British sanitary engineers of the Victorian era. But it's no use asking for the "dubbel-you-see." In France it is "doobel-vay-say" and in Germany, just "vay-tsay." "WC" may be found on door plaques but is being superseded by gendered pictograms. A plaque bearing the word "Abort" never fails to amuse, or puzzle, British visitors to Germany on their first visit to that country. Abort is rather formal German, and has been corrupted from Ab(gelegener) Ort, meaning "out-of-the-way place."

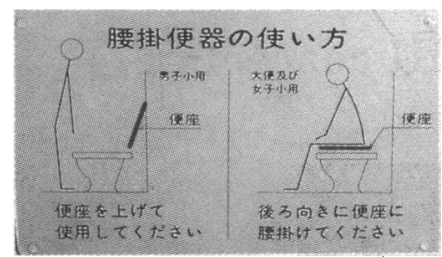

The International Allergy Congress of 1973, held in Tokyo, was followed by a week's touring for participants. To my Western eyes the most interesting lavatory plaque was within the cubicle of the ultra high speed "bullet" train (figure). This instructed visitors in the correct use of a Western style lavatory. As well as written information in Japanese, a matchstick man diagram made this plain in a way that rendered language superfluous. The gist of the message was, "If you wish to defecate, bring the seat down and sit on it. Do not climb on to the seat and squat." With tourists from all parts of the world, the Japanese must have met with some strange and exotic practices. 